\title{
Variation of reaction forces on the axles of the road train depending on road longitudinal slope
}

\author{
Shaukat Khakimov ${ }^{*}$, Erkin Fayzullaev, Azimjon Rakhmonov, and Rustam Samatov \\ Tashkent state transport university, Tashkent, Uzbekistan
}

\begin{abstract}
The article discusses the influence of the road longitudinal slope on variation in reaction forces on the wheels of the road train. The description of the longitudinal slope of the road and methods of its determination are given. The design diagram of the forces and moments acting on the road train during its movement uphill and downhill is presented. Equations for calculating the change in the load on the three axles of the road train, depending on the longitudinal slope of the road and the mode of movement, are presented. Based on the calculation results, graphs were constructed to illustrate the change in loads on three axles of the road train. The results show that the changes in the normal reactions on the front axle of the road train are significant, affecting the braking properties and driving safety of the vehicle. The scheme for calculating the variation in loads on the axles of a road train can be used to automatically adjust the braking forces between the wheels depending on the loads and thereby ensure traffic safety.
\end{abstract}

\section{Introduction}

The terrain, according to the operating conditions of vehicles, depending on the altitude above sea level, is divided into a flat (up to $500 \mathrm{~m}$ ), hilly $(500-1000 \mathrm{~m})$, mountain (1000$2000 \mathrm{~m}$ ), and high mountain (over $2000 \mathrm{~m}$ ) [18]. And also, mountainous operating conditions are determined by the geographical location of the area, which is a combination of hills, plateaus, high mountain passes, winding deep gorges, numerous ravines, and watercourses. Therefore, mountain roads are extremely diverse in nature and some indicators, for example, such as the intensity of the change in the slopes of the longitudinal profile, the degree of tortuosity of the route plan, the difference in elevation, etc., fundamentally differ from the roads in flat terrain.

Mountain regions occupy about $22 \%$ of the territory of Uzbekistan [8, 13]. Difficult terrain in mountainous regions has a great impact on the mode and safety of vehicles. The large length of sections with maximum longitudinal slopes, curves of small radii in the plan, often with unsecured visibility, force drivers to dramatically change the modes of vehicle movement, which often leads to emergencies. The greatest influence on the speed and safety of motor vehicles on mountain roads is exerted by curves in terms of a small radius with large turning angles, the number of which is $2-3$ per $1 \mathrm{~km}$. Mountain highways in Uzbekistan make up about $3 \%$ of the total road network.

* Corresponding author: shaukathawk@gmail.com 
The road and climatic conditions of mountainous terrain negatively affect the performance of vehicles, their units, and mechanisms. When the car is lifted, the engine power is reduced by $10-13 \%$ for every $1000 \mathrm{~m}$ to a height of $3000 \mathrm{~m}$ due to the deterioration of filling the cylinders with air [18]. Cooling of the engine also sharply deteriorates due to a decrease in the boiling point of water (on average $5^{\circ} \mathrm{C}$ for every 1500 $\mathrm{m}$ of altitude), a decrease in fan performance, and heat transfer from the radiator to the environment.

Overheating of the engine causes the oil in the crankcase to dilute and impairs its performance. Meanwhile, a decrease in oil viscosity can cause increased wear of engine parts.

With an increase in the altitude of the terrain above sea level, the operating conditions of electrical equipment deteriorate, the insulation resistance of electrical wires and devices decreases, the evaporation of electrolytes from storage batteries increases, and the reliability of parts and devices decreases.

On average, in mountainous areas, $12-15 \%$ of the vehicle's path is covered using the brakes. On long descents, the temperature of the brake linings reaches $350-400^{\circ} \mathrm{C}$, brake drums $-280-300^{\circ} \mathrm{C}$, as a result of which the braking distance increases by 2 times or more in comparison with the permissible one.

To study the influence of meteorological conditions on the power and efficiency of the engine [14], the method of analytical determination of the influence of temperature and air pressure on the coefficients of filling and excess air, indicator efficiency, and the value of mechanical losses was applied, i.e., on those parameters that are included in the formulas for power and fuel consumption selected for analysis.

As emphasized in several works, the operation of vehicles in mountain conditions makes its own certain adjustments $[1,14]$, which affect not only the field of technical operation but also the commercial sphere. The performance of a vehicle, therefore, transportation processes, in mountainous conditions may be extreme. It is also associated with the deterioration of the braking properties of the road train in mountainous conditions. Since the braking force of the vehicle depends on the load on the wheel. This can lead to an overturning of the front axle, slipping of front wheels of the vehicle, and deterioration of road safety. Thus the particular study of the influence of longitudinal slope of the road on reaction forces on wheels of the road train becomes significant.

\section{Methods}

Automobile transportation of goods over sufficiently long distances is carried out mainly by road trains consisting of a tractor and trailers and a truck tractor with a semitrailer. The vehicle's operation with a semitrailer has several advantages: maneuverability, adaptability to container transportation, versatility and the ability to change the semitrailer platform to different cargoes, transportation of liquid, bulk cargo by tank semitrailers, as well as long, oversized cargo.

On the roads of flat regions, the operation allows increasing the overall length of the road train to the size permitted by the standards. Mountain road conditions make adjustments to the requirements for the formation of road trains.

The design feature of the link between the links of the road train, the change in the loads on the links, therefore, on the axles of the vehicle, when moving up or down, the dynamic modes of acceleration or braking can significantly affect the traction properties and performance of the road train. And this obliges, analyzes the distribution of normal loads along with the axles of a semitrailer train in the study of their efficiency in mountain conditions.

The distribution of loads along the axes of the vehicle depending on the slope of the 
road can be determined by experimental or calculation methods. Let us present the results of computational and experimental studies to study the influence of the longitudinal slope of the road on the redistribution of loads along the axes of a particular road train $[4,10,19$, 20].

The research object was a road train consisting of a MAZ-642208-020 truck-tractor and a semitrailer "Istanbul-Fruehauf," operated in the conditions of the Kamchik pass.

Figure 1 shows the forces and moments acting on a towing vehicle and a semitrailer when driving uphill.

The range of variation of the longitudinal slope of the road is taken according to the technical parameters of the road; the modes of acceleration or braking are also taking into account the operating conditions and technical capabilities of the truck tractor.

\subsection{Methods for determining the longitudinal slope of the road}

The design line of individual road sections is characterized by longitudinal slope $i$ between two points, i.e., the ratio of the difference in heights $h$ between these points to the horizontal distance between them a. The longitudinal slope is determined by the tangent of the angle of inclination of the line to the horizon (Figure 1) [17]:

$$
i=\operatorname{tg} \alpha=h / a
$$

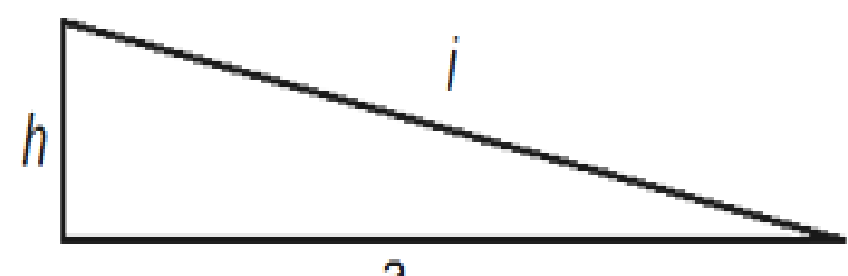

a

Fig. 1. Design scheme for longitudinal slope determination: $i=\operatorname{tg} \alpha=h / a$ is slope (without unit); $i=\operatorname{tg} \alpha=100 \mathrm{~h} / \mathrm{a}$ is slope in \%; $i=\operatorname{tg} \alpha=1000 \mathrm{~h} / \mathrm{a}$ is slope in \%o (ppm);

The slope value $i$ is expressed as a percentage, in ppm (thousandths) or in relative units: $i=3 \%$, or $i=30 \%$, or $i=0.03$. The slope value in ppm shows how many meters the route of the road axis rises or falls over $1000 \mathrm{~m}$. Uphill is considered as positive, and downhill is as negative slope.

In geodetic surveys, a non-horizontal distance is measured between two points, directly along the earth's surface. Therefore, in fact, the slope is calculated not as $\operatorname{tg} \alpha$, but as $\sin \alpha$ :

$$
l=\sin \alpha=h / i
$$

Considering that the angle of the longitudinal slope of the road route does not usually exceed $3 \ldots 4^{\circ}$, we can assume $\sin \alpha \sim \operatorname{tg} \alpha$. Longitudinal slopes of roads and streets must meet the requirements, the observance of which ensures normal driving conditions. Although modern vehicles can climb significant gradients on short, dry sections, travel speeds are noticeably reduced. On slippery or muddy road surfaces, the uphill speed will be even lower.

When designing the longitudinal profile of roads and streets, fractures are formed at the intersection points of adjacent sections with different slopes. The close distance between the fractures of the longitudinal profile and especially the frequent alternation of ups and downs interfere with the convenience of movement since they require a change in the 
driving mode, gear shifting, and sometimes braking. Therefore, it is advisable to observe the possible large distances between the profile fractures. Distinguish between convex and concave profile fractures. Convex fractures interfere with the smoothness of movement and impair the view of the road ahead of a moving vehicle. On concave fractures, shocks and overloading of the springs occur under the action of centrifugal force.

There are many ways to determine the pitch of a road. One of them is the determination of the longitudinal slope of the road depending on the vehicle's speed. At the same time, the vehicle is moved with a fixed position of the accelerator pedal along road sections with known values of longitudinal slopes, and a relationship is established between the values of these slopes and the vehicle speed. On the investigated section, a vehicle speed is measured, and the determination of the longitudinal slope of the road section is carried out according to the established relationship. There is also a known method for determining the longitudinal slope of the road using aerial photography. Aerial photography of the area is performed by aerial cameras installed in the cockpits of aircraft and additional equipment that determines the position of aerial photographs at the time of their photographing in space. Stereoscopic photographs obtained in the course of aerial photography are processed on a stereo meter. In this case, the determination of the slopes is reduced to taking readings from the longitudinal parallax screw after aiming the stereo filament at the image of the observed points. The disadvantages of this method include the high complexity of measurements and the processing of results.

\subsection{Determination of the dependence of reaction forces on the wheels of the road train on the road longitudinal slope}

To determine $Z_{1}$ the balance of moments relatively to point $O_{2}$ is used (Figure 2 a).

$$
\begin{aligned}
& -Z_{1} L_{T}-G_{T}\left(h_{g m} \sin \alpha+r_{\partial} f \cos \alpha+\delta_{B p} j_{a} / g\right)- \\
& -P_{B} h_{B}+b G_{T} \cos \alpha+P_{C Z} L_{0}-P_{C X} h_{p}=0
\end{aligned}
$$

It leads to,

$$
Z_{1}=\frac{b G_{T} \cos \alpha-G_{T}\left(h_{g m} \sin \alpha+r_{\partial} f \cos \alpha+\delta_{B p} j_{a} / g\right)-P_{B} h_{B}+P_{C Z} L_{0}-P_{C X} h_{p}}{L_{T}}
$$



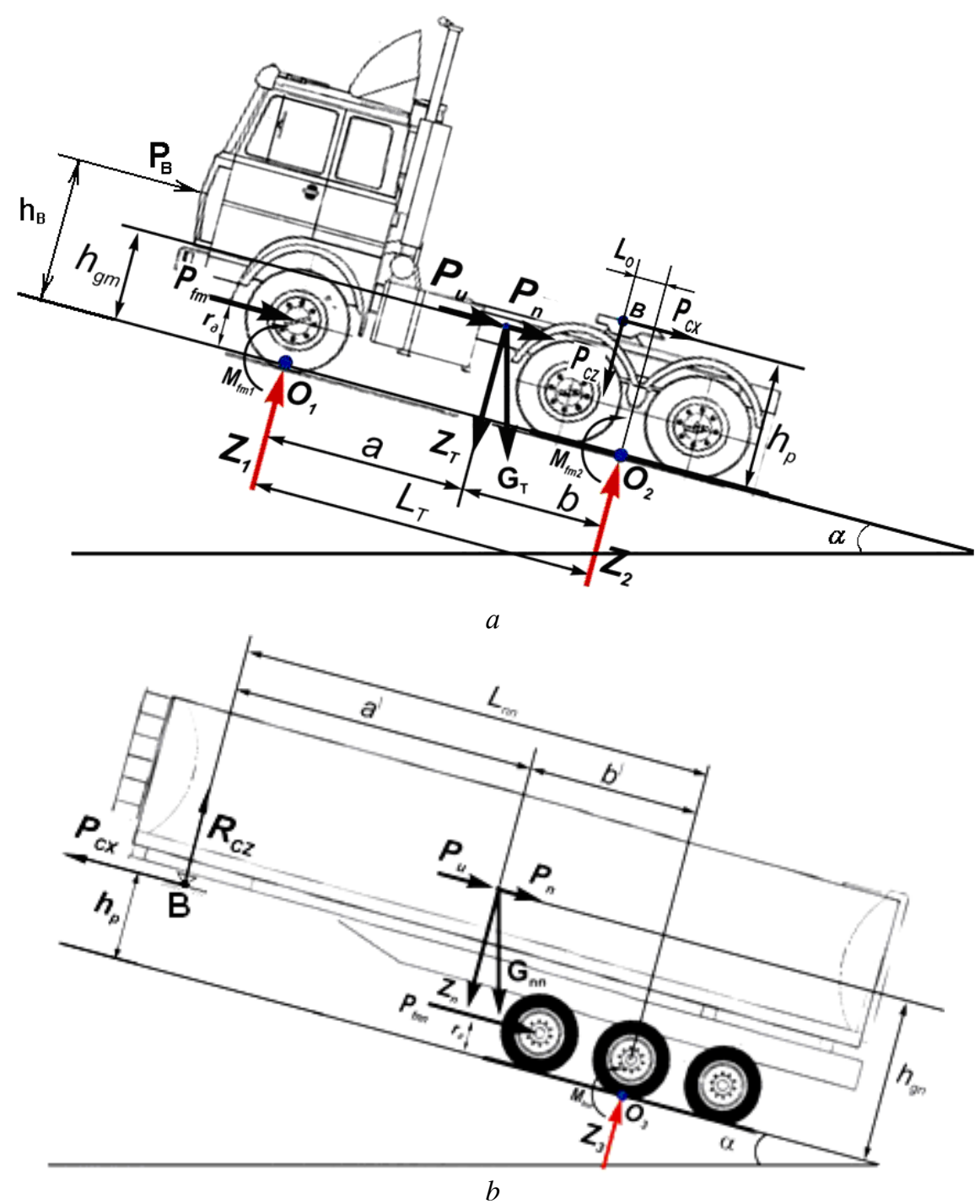

Fig.2. Design schemes for vertical movement with road trains on the uphill: $a$ is trucktractor; $b$ is semitrailer

By the same way $Z_{2}$ is defined relatively to point $O_{1}$ :

$$
Z_{2}=\frac{G_{T} \cos \alpha\left(a+f r_{\partial}\right)+G_{T} h_{g m}\left(\sin \alpha+\delta_{B p} j_{a} / g\right)+P_{B} h_{B}+P_{C X} h_{p}+P_{C Z}\left(L_{T}-l_{0}\right)}{L_{T}}
$$

For a semitrailer, the reaction on the fifth wheel coupling $R_{C Z}$ is equal to $P_{C Z}$ with opposite direction $\left(P_{C Z}=R_{C Z}\right)$.

Traction force on the fifth wheel coupling $P_{C X}$ is equal to semitrailer movement resistance force

$$
P_{C X}=G_{n n}\left(f \cos \alpha+\sin \alpha+j_{a} / g\right)+P_{B}
$$


Therefore,

$$
\begin{gathered}
R_{C Z}=P_{C Z}=\frac{G_{n n} \cos \alpha\left(b^{\mid}-r_{\partial} f\right)-G_{n n} h_{g n}\left(\sin \alpha+j_{a} / g\right)-P_{B} h_{B}+P_{C X} h_{p}}{L_{n n}} \\
Z_{3}=\frac{G_{n n}}{L_{n n}}\left(a^{\mid} \cos \alpha+\left(h_{g n}-h_{p}\right)\left(\sin \alpha+\delta_{B p} j_{a} / g\right)+r_{\partial} f \cos \alpha\right)+\frac{P_{B} h_{B}}{L_{n n}}
\end{gathered}
$$
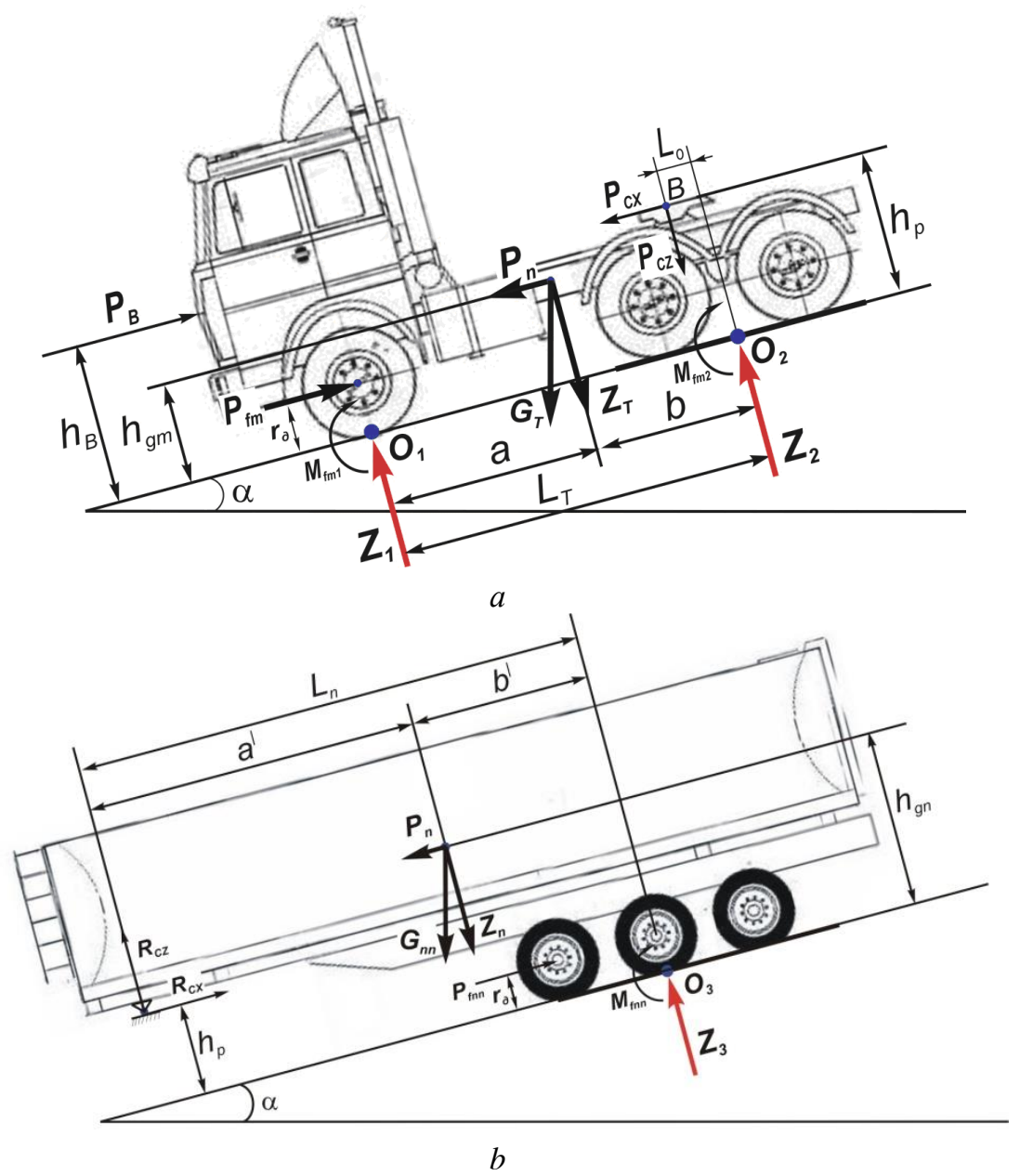

Fig.3. Design schemes for determining vertical reactions when driving a road train on a downhill: $a$ is truck-tractor; $b$ is semitrailer

When driving downhill, the force from the longitudinal slope of the road $P_{n}$ and the force of inertia $P_{u}$ (when the road train moves with deceleration) are converted into forces that drive the road train into motion; that is, these forces are taken with the opposite sign in expressions than when moving uphill (Figure 3). Thus, the normal reactions on the wheels of the road train when driving downhill are determined by the following expressions: 


$$
\begin{gathered}
Z_{1}=\frac{b G_{T} \cos \alpha-G_{T}\left(r_{\partial} f \cos \alpha-h_{g m} \sin \alpha-\delta_{B p} j_{3} / g\right)-P_{B} h_{B}+P_{C Z} L_{0}+P_{C X} h_{p}}{L_{T}}, \\
Z_{2}=\frac{G_{T} \cos \alpha\left(a+f r_{\partial}\right)-G_{T} h_{g m}\left(\sin \alpha+\delta_{B p} j_{3} / g\right)+P_{B} h_{B}-P_{C X} h_{p}+P_{C Z}\left(L_{T}-l_{0}\right)}{L_{T}}, \\
Z_{3}=\frac{G_{n n}}{L_{n n}}\left(a^{\prime} \cos \alpha-\left(h_{g n}-h_{p}\right)\left(\sin \alpha+\delta_{B p} j_{3} / g\right)+r_{\partial} f \cos \alpha\right)+\frac{P_{B} h_{B}}{L_{n n}} \\
P_{C X}=G_{n n}\left(\sin \alpha+j_{3} / g-f \cos \alpha\right)+P_{B}, \\
R_{C Z}=\frac{G_{n n} \cos \alpha\left(b^{\mid}-r_{\partial} f\right)+G_{n n} h_{g n}\left(\sin \alpha+j_{3} / g\right)-P_{B} h_{B}-R_{C X} h_{p}}{L_{n n}}
\end{gathered}
$$

Graphs of dependences of changes in normal loads on the mode of movement of the road train can be made in condition $Z_{i}=f(\alpha), Z_{i}=f(j), Z_{i}=f(V)$ (Figures 4-6).

It is possible to determine the influence of the road slope on the redistribution of loads and compare them with the normal loads on the axles of a road train on a horizontal road with the help of functions $Z_{i}=f(\alpha), Z_{i}=f(j), Z_{i}=f(V)$.

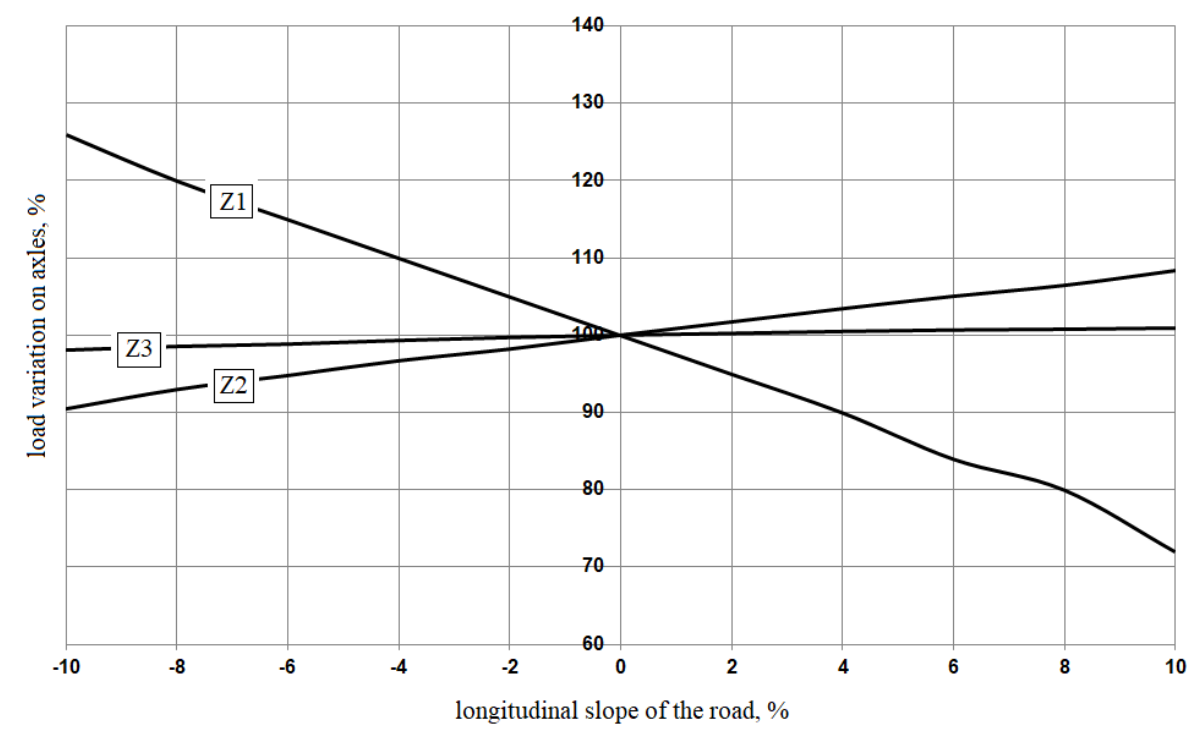

Fig.4. The influence of the road longitudinal slope on changes in normal loads on the axles of the road train. 


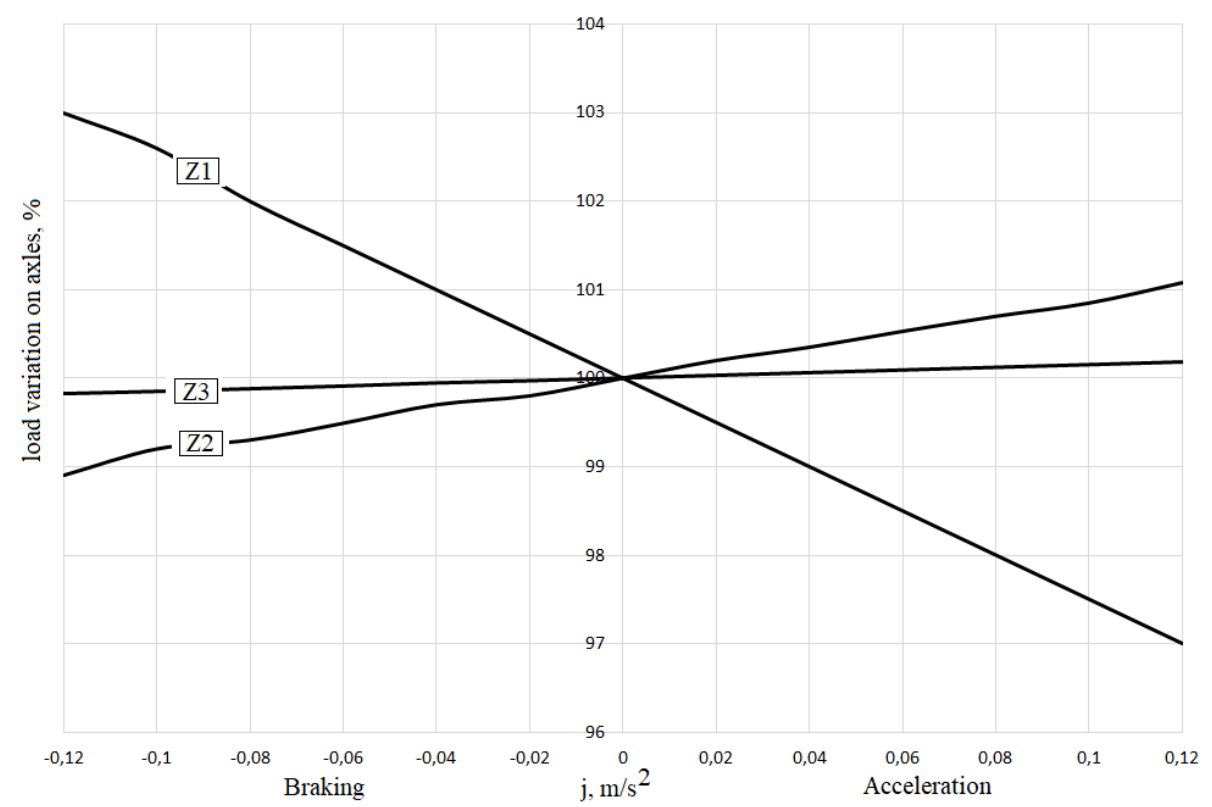

Fig.5. The influence of acceleration and deceleration on changes in normal loads on the axles of the road train

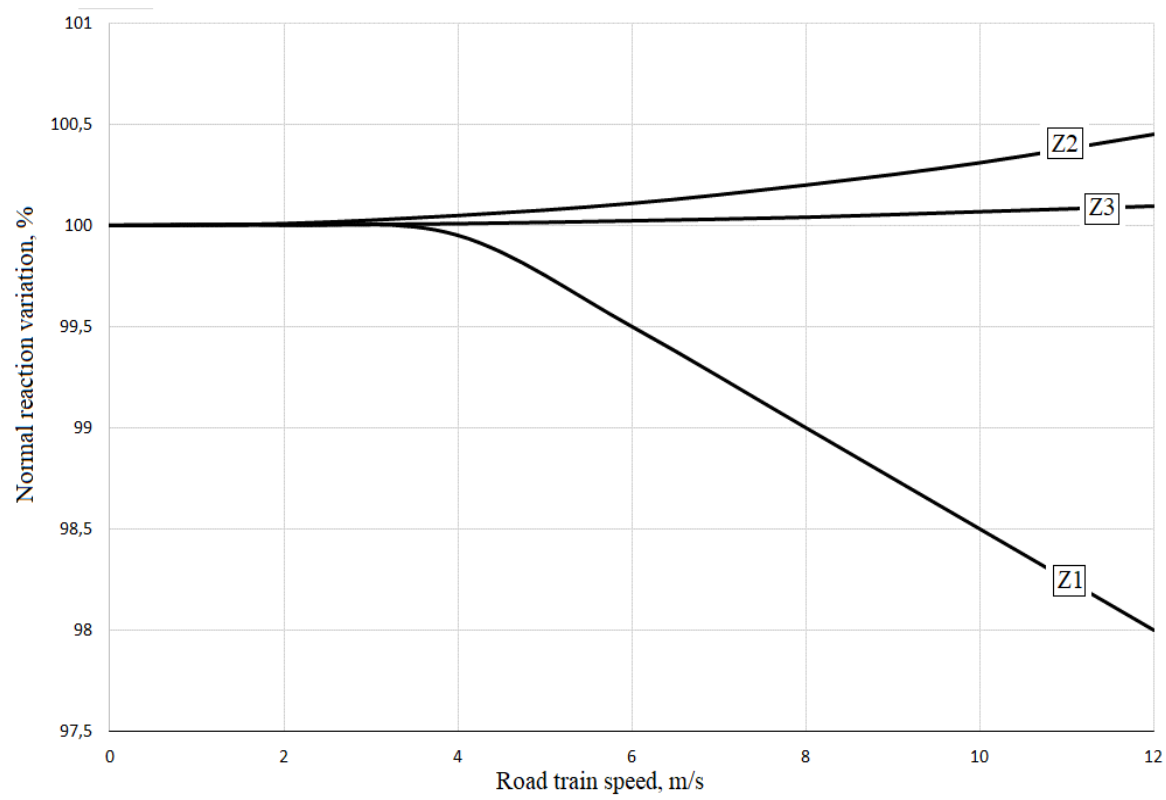

Fig. 6. The influence of the speed of the road train on changes in the normal loads on the axles

The longitudinal slope of the road has a significant impact on the traction-speed and fuel-economic indicators. When transporting goods along the same route in opposite directions in mountainous terrain, productivity, therefore, the economic indicators of transport work will differ. 


\section{Results and Discussions}

The design scheme of forces and moments acting on a towing vehicle and a semitrailer when moving on uphill and downhill is built. The dependences of normal loads on the axles of the road train on the longitudinal slope of the road and the mode of movement of the road train are obtained. The results show that a large change in the loads on the axles of the road train when driving uphill and downhill occurs on the front axle. For example, on the road with a slope of $8 \%$, the change in $\mathrm{Z} 1$ is $20 \%$, while the changes in $\mathrm{Z} 2$ and $\mathrm{Z} 3$ are $7 \%$ and $1 \%$, respectively. Also, during the acceleration and deceleration of the road train, the change in Z1 is greater than Z2 and Z3. Sometimes there are ascents with a slope of up to $12 \%$ Troll Road (Norway), then, according to calculations, on such slopes, Z1 decreases by more than $30 \%$. This can lead to an overturning of the front axle, sipping the vehicle's front wheels, and deterioration of road safety. It is also associated with the deterioration of the braking properties of the road train in mountainous conditions. Since the braking force of the vehicle depends on the load on the wheel.

\section{Conclusions}

There are many countries in the world with mountain roads and where goods are transported by road trains. Sometimes these roads play a life-supporting role. In Uzbekistan, 3 regions are connected with the remaining 10 regions only through the Kamchik mountain road. Such an example can be cited by countries such as Kyrgyzstan, the roads in the Caucasus, the Netherlands, Italy, Switzerland, France, Nepal, European countries that are connected through the Alpine mountains, Latin America and Africa. It can be seen that the geography of this problem is large-scale.

This method of determining the change in loads on the axles of a road train is useful in ensuring their safety when operating in mountainous conditions. Knowing the longitudinal slope of the road in mountainous terrain, it is possible to calculate the change in axle loads and its effect on the braking properties of the road train. The scheme for calculating the change in loads on the axles of a road train can be used to automatically adjust the braking forces between the wheels depending on the loads and thereby ensure traffic safety.

\section{References}

1. Alikhodjaev A Management of standards for automobile service and repairs taking into account using conditions. Tashkent. (2008)

2. Scientific Report, Selection of effective type of the truck to use in transportation of oil products through Kamchik pass. (2008)

3. Zagorodniy N, Enhancing the efficiency of the automobile by providing the rational parameters of its tires. Belgorod. (2010)

4. Ivanov A, Automobiles, Theory of exploitation properties. Moscow. (2013).

5. lama B, System development for automobile use in tropic climate conditions and mountain area (in example of Guinea). Minsk, (1994)

6. Lechashvili G, Enhancing the efficiency of the automobile in condition of mountain region. Minsk (1989).

7. Magomedov M. Mountain roads (Features of design, construction and exploitation of the example of Dagestan). Moscow (2006).

8. Mirzabekov M, Features of the movement regime and safety on the mountain roads of Uzbekistan. Tashkent.( 2016)

9. Mukhitdinov A Khakimov Sh, Monograph: Improvement of the methodology for 
enhancing the efficiency of commercial vehicles. Tashkent. (2017).

10. Mukhitdinov A Khakimov Sh, Analyses of the relation between specific efficiency and exploitation parameters of the road train. Tashkent (2011).

11. Nusupov E, Enhancing the efficiency of the vehicle in mountain conditions. Moscow. (1991).

12. Tursunov A, Managing the vehicle performance in mountainous conditions. Vladimir. (2002)

13. Urakov A, Evaluation of the traffic safety on the mountain automobile roads of Uzbekistan. Tashkent. (2001)

14. Fayziev M, Enhancing the performance efficiency of the diesel engine KamAZ-740 in mountainous conditions. Tashkent. (1993).

15. Fayzullaev E Khakimov Sh, Influence of rolling masses of the vehicle to its traction performance. Tashkent. (2008).

16. Fayzullaev E Khakimov Sh, Interpolation of the engine performance in modeling the automobile ride by software Maple-11. Tashkent. (2009)

17. Furman F, Influence of longitudinal slope of the road to exploitation efficiency of excavator-automobile complexes. Russia (2015).

18. Khakimov Sh Sattivaldiev B, Evaluation of traction performance of the road train. Tashkent. (2007)

19. Rajesh Rajamani, Vehicle dynamics and control. Springer Science + Business Media, Germany, 2012, pp 496. (2012).

20. Wong J, Theory of ground vehicles. 4th Edition. Wiley (2008).

21. Feng $\mathrm{H}$ et al, Modeling the impacts of related factors on traffic operation. Procedia Eng (12), pp 99-104 (2011) 